\title{
Leiomyoma of levator ani muscle
}

\begin{abstract}
Epithelioid leiomyomas of the vagina are extremely rare benign smooth muscle tumors. Leiomyomas are located in uterus in 70\%; however, paravaginal leiomyomas are rare, which frequency is $0.1 \%$ in adults women. They can be asymptomatic, but if they are, may cause signs of compression, dyspareunia, urinary disorders,... The diagnosis is made by histologic and immunohistochemical examination, helped by imaging tests such as RMN and ultrasound. The first treatment option is the resection by enucleation. Search of information was carried out in the PubMed/Medline, Cochrane, SciELO databases and references from articles in journals and recent published texts. This is a case report of a 29-years-old female who is derived to Gynecologic Emergencies because of a Bartholinitis refractory to antibiotic treatment. The gynecological exploration reports a vaginal mass which extends to left paravaginal space. The biopsy of this mass suggests the diagnosis of leiomyoma. MRI study reports a 49mm mass in left ischiorectal space which seems to depend on puborectal muscle. The resection is made by enucleation, with a histopathological examination that confirms the diagnostic suspicion.
\end{abstract}

Volume 12 Issue 3 - 202I

López Gonzalez Elga,' Escribano Cobalea
María, ${ }^{2}$ Peña Salas María Soledad'
'FEA Obstetrics and Gynecology. Juan Ramón Jimenez Hospital.
Huelva
${ }^{2}$ FEA Obstetrics and Gynecology. Punta Europa Hospital.
Algeciras

Correspondence: Elga López González, Gynecology and Obstetrics Secretary of the Juan Ramón Jimenez Hospital, Huelva, Spain,Tel +34647509546, Email elga_t@hotmail.com

Received: May 09, 2021 | Published: May 27, 2021

Keywords: leiomyoma, puborectal, mass, bening tumors, paravaginal

\section{Introduction}

Vaginal leiomyomas are rare. These solid benign tumors can manifest clinically in adult women with the appearance of a mass that produces signs of compression, dyspareunia, menstrual and urinary disorders. ${ }^{1}$ Estrogens and epidermal growth factor play a role important in its evolution and growth. ${ }^{2}$ Its diagnosis is made through physical examination, vaginal ultrasound and extension study. Once diagnosed, the preferred option is excision to avoid sarcomatous changes. ${ }^{3}$ Otherwise, if the patient prefers to maintain an expectant attitude, a biopsy is recommended to have histopathological confirmation of its benign nature.

\section{Methodology}

Search for information in databases such as PubMed/MEDLINE, Cochrane and SciELO, based on the terms paravaginal leiomyoma, anorectal leiomyoma and vaginal tumors; as well as in references to magazine articles and texts, mainly from the last five years.

\section{Clinical case}

A 29-year-old patient, with no personal background of interest except two previous pregnancies, who came to the emergency room for Bartholinitis treated in Primary Care refractory to treatment. Pelvic examination reveals a tumor in the proximal part of the vaginal wall, with solid consistency, deepening towards the left paravaginal space, non-fluctuating, without signs of infection. The mass was freely mobile, without infiltration or fixation to adjacent structures. The paravaginal ultrasound reveals a solid mass of $29 \times 35 \mathrm{~mm}$. It was taken a biopsy under local anesthesia which, after histopathological examination, reveals a benign mesenchymal tumor, with an immunohistochemical study that revealed positive staining for smooth muscle actin, suggesting the diagnosis of leiomyoma (S100 negative, Ki67<1\%).

Since the mass was symptomatic, it was decided to excise the lesion. In a preoperative study, an extension study with MRI is requested for its correct surgical approach, reported as: focal lesion of $49 \mathrm{~mm}$ in maximum diameter in the left ischioanal space with probable dependence on the puborectalis muscle and may correspond to leiomyoma.

The histopathological examination confirmed the diagnosis of leiomyoma (positive actin and desmin staining, other negative markers (S100, CD31 and RE)).

\section{Discussion}

Leiomyomas are the most common gynecologic tumors and are seen in about $20 \%$ of women over 35 years of age. Most of these tumors develop in the uterine smooth muscle; however, other extrauterine gynecological locations are known including fallopian tubes, cervix, round ligament, ovary, utero-sacral ligament, and urethra. A single firm, globular or polypoid-like mass that is evidenced in the vagina, is usually a pedunculated myoma from the cervix or even the uterine cavity. Leiomyomas that develop de novo from the fibromuscular elements of the vagina are a rare entity. When these tumors appear in the upper part of the vagina, they are usually confused with cervical fibroids. ${ }^{4}$ When these are of the lower third, as we can see in our case report, they can be confused with Bartholinitis.

The clinical course of these tumors is highly variable, the location and vascularization are mostly factors that determine the patient's symptoms. Due to their submucosal origin, they are often asymptomatic in early stages. Later, when they reach significant sizes, there are usually symptoms of compression such as anal and perineal pain, alterations in intestinal transit, itching, rectal bleeding, tenesmus, voiding syndrome, dyspareunia, are some of the most frequent symptoms for which the patient consults. ${ }^{2,5}$

The diagnosis can be made from the pelvic examination or with some image testing such as ultrasound, urethrocystography, urethrocystoscopy, tomography or magnetic resonance. ${ }^{6}$ Ultrasound, tomography and magnetic resonance images resemble those of cervical myoma. They are frequently confused with other vaginal tumors and the correct diagnosis is made with histological examination.?

Macroscopically, the leiomyoma appears as a solid tumor, with elastic consistency because it is made up of muscle and collagen, well 
defined, with a fascicular appearance and a pearly-white, gray-white or reddish color when cut, depending on the vascularization; can be covered by ulcerated or non-ulcerated mucosa. ${ }^{8}$

Histologically, they are made up of mature smooth muscle cells with abundant eosinophilic cytoplasm, organized in interlaced bundles devoid of atypia and necrosis, and with mild mitotic activity $\left(<1\right.$ mitosis/50 high-power fields). ${ }^{9}$

The differential diagnosis includes other vaginal tumors, such as: Gartner, Bartholino or Skene gland cysts, urethral diverticula, urethrocele, cystocele, rectocele and neurofibromas. ${ }^{6}$

Excision and enucleation is the treatment option in all series. Its vaginal excision can cause severe bleeding, especially if the base of the tumor cannot be reached in its entirety or if it is located in the upper third of the vagina. In some cases the approach of choice is the abdominal route and in others an abdominoperineal approach is required. ${ }^{10}$

\section{Acknowledgments}

None.

\section{Funding}

None.

\section{Conflicts of interest}

The authors declare no conflicts of interest in preparing this article.

\section{References}

1. Rodríguez Pons Orlando M, Guzmán García Jesús. Mioma vaginal. Rev Cubana Obstet Ginecol. 2017;43(3):152-156.

2. Mónica RF, Irene GG, Sara CD, et al. Leiomioma vaginal de crecimiento rápido. Reporte de un caso. Ginecol Obstet. Méx. 2018;86(10):687-691.

3. Pantoja Garrido M, Frías Sánchez Z, Tato Varela S, et al. Mioma vaginal intraabdominal, masa pélvica de localización atípica. Rev Cuba Obstetr Ginecol. 2016;42(3).

4. Carmen M, Juan RC, Morao Carmen C. Mioma vaginal: reporte de un caso. Rev Obstet Ginecol Venez. 2011;71(1):65-67.

5. Sui Y, Sun C, Lv S, et al.Perineal leiomyoma in a postmenopausal woman: A case report. Oncol Lett. (2016);12(3):2045-2047.

6. Egbe TO, Kobenge FM, Metogo JAM, et al. Vaginal leiomyoma: medical imaging and diagnosis in a resource low tertiary hospital: case report. BMC Women's Health. 2020;20(1):12.

7. Nel CP, Tiltman AJ. Leiomyoma of the vagina. $S$ Afr Med J. 1978;54(20):816-817.

8. Cheong MS, Koo DH, Kim IS, et al. Concurrent multilocular cystic renal cell carcinoma and leiomyoma in the same kidney: previously unreported association. Case Rep Oncol. 2010;3(2):218-222.

9. Uzcátegui-R YC, Rodríguez-U AA, Flores LR, et al. Leiomioma perianal. Reporte de un caso. Avan Biomed. 2014;3:93-97.

10. Carmen M, Juan RC, Morao Carmen C. Mioma vaginal: reporte de un caso. Rev Obstet Ginecol Venez. 2011;71(1):65-67. 